\title{
The Development of Educational Youtube Videos-Based Instructional Material for Speaking for Beginner Course
}

\author{
Syifa' Khuriyatuz Zahro, syifazahro@unisda.ac.id, Department of English Education, \\ Darul 'Ulum Islamic University Lamongan, Indonesia \\ Fariq Shiddiq Tasaufy, tasaufy@unisda.ac.id, Department of English Education, Darul \\ 'Ulum Islamic University Lamongan, Indonesia
}

\begin{abstract}
An analysis of the students' needs demonstrated that there is no primary instructional material of speaking for beginners utilized in the classroom. Besides, both lecturers and students preferred the utilization of an authentic audio-visual material like YouTube videos rather than a traditional material taken from textbooks to accelerate their speaking proficiency. The current study sought to develop educational YouTube videos-based instructional material of speaking for beginner course through Borg \& Gall model that cover three main stages out of ten stages; preliminary research, model development, and model validation. Fifty-nine students who attended speaking for the beginner course of three universities in Lamongan, Darul Ulum Islamic University, Billfath University, and the Islamic University of Lamongan participated in the try-out stage. The instruments are questionnaire and interview guidance that was adapted from Djahida, while the validation checklist was adopted from Beaudin and Balasubramanian, Shetty \& Sathyanarayana.The instructional material developed in this study is so-titled 'Speaking for Beginner: A way to speak like natives.' The acceptability revealed in the students' evaluation at the try-out demonstrates that the material was generally good and acceptable for the students and the lecturers. Such results bring about the conclusion that 'Speaking for Beginner: A way to speak like natives' is suitable and applicable to the speaking for the beginner classroom.

Keywords: educational YouTube videos, instructional material development, speaking for beginner, speaking course
\end{abstract}

\section{INTRODUCTION}

In this industrial revolution where global exchange, interconnectivity, international interaction, and communication are greatly enhanced, people are inevitably required to be able to communicate in English and make the English communication intelligible as well as acceptable, particularly for communicating to the English native speakers (Zahro, 2019). The communicative competence in English is what supposed to be the objective of speaking classes. Speaking implicates a meaning building in an interactive way by which a speaker produces, receives information and delivers it verbally (Brown H. Douglas \& Heekyeong, 2015). Hence, speaking is one of a productive oral skill that emphasizes on communicative competence practices to express thought.

At the university level, speaking for the beginner is of speaking courses that are provided for the freshman of university students in their first semester. It is of scientific and skill courses (Mata Kuliah Keilmuan dan Keterampilan/ MKK) that oriented to give fundamental science and skill as written in the decree of minister of national education Indonesia No. 232 the year 2000 (Depdiknas, 2000). Therefore, the objective of speaking for 
a beginner course must be related to the students' ability to understand the fundamental theory of speaking and practice to speak on various topics that grant the students' communicative competence. The earlier preparation of material development in the students' first year is expected to give the foundation of the former speaking classes and provide an insightful learning experience.

The preliminary survey conducted to the students who have attended speaking classes revealed that the majority of the student thought speaking is difficult, yet few of them found it easy. The perception of English speaking difficulty is triggered by several problems they confronted when they are attempting to speak English: hard to express ideas due to lack of vocabulary, fear of making a mistake, lack of self-confidence, and teachers' negative feedback. The abovementioned survey results confirm the need to evaluate the speaking classes, especially to develop primary instructional material for speaking courses. This is because it was found that still no primary instructional material of in-class speaking courses, including speaking for a beginner course.

Furthermore, the result of the analysis of the students' needs indicated that almost all of the students preferred the exposure to English native speakers' talk videos rather than written textbook and all of them supported the use of native speaker videos in speaking class. They justified that their experience of listening to native speakers' talk allows them to duplicate native speakers' way of speaking directly. This is as agreed by the lecturer who confirmed the utilization of authentic audio-visual material like videos is much more advantageous rather than textbook material in accelerating students' speaking proficiency. The utilization of audiovisual materials power had been known as an effective way to catch the students' attention and enhance their motivation as well as their learning experience (Cruse, 2018).

A previous related study found is an accelerated learning-based approach speaking material development that aimed at encourages English education students of the third semester in IAIN North Sumatra to use English as a means of communication in both formal and non-formal context by considering authenticity, relevance, consistency, and adequacy aspect (Santoso, 2014). Another preceding study is the speaking material development toward the second semester in STAIN Samarinda which has developed a final product consists of 10 chapters; school life, my experience, experiencing nature, stories, in the community, mass media, social life, entertainment in social life, and is smooth and confident (Fauzan, 2014). The subsequent relevant study is the development of reading contextual internet-based instructional materials through the implementation of teaching integrated reading and speaking (TIRS) in EFL students' speaking IV class that generates the students' speaking skill enhancement in their active participation, abilities to deliver a presentation, to ask and answer questions, to comment and argue in a discussion. The contextual consideration in theme selection was based on their interest was a key of the enhancement (Manurung, 2015).

Among the abovementioned previous study, none of the speaking material that had been developed employs an audio-visual-based materialthat allows the students to have various exposures to English native speakers' talk as needed by the students and agreed by the lecturers as the result of need analysis. This signifies the importance ofthe development of the speaking material according to the need analysis result.

Implementing audio-visual materials to advance speaking skill has been evidenced its success by Djahida (2017)that investigated the role of educational YouTube videos to improve EFL students' speaking skill to second-semester students of Biskra University. The result showed its effectiveness not only to promote students' communicative competence but also enhance their self-confidence, contextual language exposure, and vocabulary enrichment (Djahida, 2017). This verified the prosperous usages of an audio-visual material like the educational YouTube videos is not only to accelerate students' English speaking competence, 
but also to increase vocabulary, confidence, and English context which are the problems confronted by the students under the study. Nevertheless, Djahida's (2017) research was investigating the role of educational YouTube videos to improve speaking skills, while this research attempted to develop the audio-visual-based speaking material which is believed to be effective in advancing students speaking skill.

In brief, the present research is attempted to fulfill the students of speaking for beginner need on a primary instructional material for speaking for beginner courses by developing speaking material through integrating audio-visual materials in the form of English native speakers' educational videos-based adopted from YouTube. Therefore, this research and development implemented educational YouTube videos as a fundamental basis of the instructional material development for speaking course.

\section{METHODS}

This study was designed as educational research and development (R\&D) that aimed to achieve development-based and product validation-based goals (Gall, Borg, \& Gall, 2007). The educational $\mathrm{R} \& \mathrm{D}$ employed in this study is adopted the language program development (LPD) by Gall, Borg \& Gall (2007), which is built-in three main stages out of ten: preliminary research, model development, and model validation. The three main stages are broken down into ten stages as the following figure.

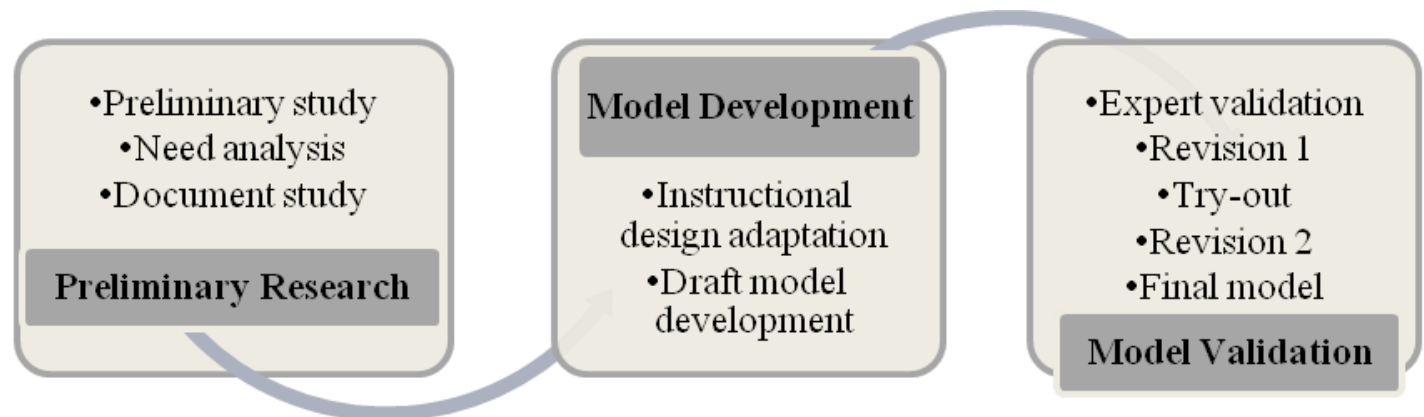

Figure 1. The Flowchart of Research and Development Stages

The source of the data in this research obtained from the participants of the study that were lecturers who are in charge of speaking for beginner course and the students of English department who have attended speaking for beginner course at three universities in Lamongan; Darul Ulum Islamic University, Billfath University, and the Islamic University of Lamongan.

In the preliminary research, a preliminary study has resulted from the instrument adaptation. The instruments are a questionnaire, and interview guidance adapted from Djahida (2017) as well as a validation checklist adapted from Beaudin (1996) and Balasubramanian, Shetty, \& Sathyanarayana (2018). In the need analysis stage, the questionnaire was distributed toward 27 students who were purposefully selected from the high, medium, and low level of speaking to generate their needs in the speaking for a beginner course. The interview guide was used to collect the data in the interview session toward the lectures. The data gained from the need analysis stage are both quantitative and qualitative. The quantitative data obtained from questionnaires were rated and presented in the percentage form. The qualitative data gained from the interview as well as the result of the percentage were analyzed descriptively. The data collected through documentation was three documents of the semester learning plan (SLP)/ rencana pembelajaran semester (RPS) of speaking course developed by the lecturers of three universities based on their experience in teaching speaking to their students. The three 
documents in the form of three SLP, as well as the result of the analysis of both questionnaire and interviews, are the fundamental basis on the first stage of model development, instructional design adaptation. The first stage of model development was developing the SLP for the future instructional material through adopting the mutual aspects of three documents and developing new designs based on the need analysis result from the questionnaire and interview result in the stage of instructional design adaptation. Next, a lesson plan (Rencana Penilaian Pembelajaran/ RPP) for speaking for beginner course was also developed based on the developed SLP for the future instructional material. As a final point, the developed SLP and RPP of speaking for beginner course was the foundation in the stage of draft model development. Besides, the stage of draft model development encompassed two main accomplishments. They were determining the topics to gain the learning material and plotting the audio-visual materials that were following the availability of educational videos on YouTube. Both topics and YouTube videos selection were then developed as a model prototype by designing the units of the model as the future instructional material. Lastly, the classroom activities and classroom speaking practice development were later completed to produce the draft model.

In the expert validation stage, the draft model was subsequently validated by the experts who are the lectures of speaking for a beginner course to be evaluated. The expert validation utilized the validation checklist adapted from Beaudin (1996) and Balasubramanian, Shetty, \& Sathyanarayana (2018) that evaluated four major aspects: content, instructional design, language, and presentation on five points Likert scale (1932). The result of validation was the basis by which the revision of the draft was made. When the revision is completed, the try-out is implemented toward four classes in the three universities. To gain more information about students' acceptability of the instructional materials, twentyseven of them were purposively selected based on three categories of speaking level: high, medium, and low to distribute evaluation checklist along with the description of each aspect given at the end of try-out. The evaluation checklist of the model was categorized as strongly agree, agree, neutral, disagree, and strongly disagree. The result of the evaluation in both the expert validation and try-out was analyzed based on the subsequent norms. If each number attains more than $80 \%$, it is interpreted as suitable and applicable, if it gets $79 \%-59 \%$ for each number, it means it is suitable and applicable enough with some revision if the number attained less than 50\%, it implies as being not suitable and not applicable and, therefore, needs to do a major revision.

\section{RESULT}

The result and discussion of this research and development are described into several sub-headings according to the stages employed in this research and development.

As an initial step to generate the students of speaking for beginner needs, a need survey was conducted toward 27 students who were purposively selected and had attended speaking for beginner course and a structured interview conducted toward the lecturers to know their perspectives and suggestion about all the need in the speaking course.

The result of the analysis revealed that more than half of students $(67 \%)$ still found speaking in English is a difficult skill to master. Their perception of speaking difficulty led some of them never (4\%), rarely (26\%), and occasionally (48\%) speak English both in class $(70 \%)$ and out of class (30\%). Their foremost problems in speaking English are hard to express ideas due to lack of vocabulary (49\%), fear of making a mistake (24\%), lack of selfconfidence $(22 \%)$, and teachers' negative feedback $(5 \%)$. Another problem found is that there is no primary instructional material for speaking classes, as found in the interview result. The 
materials used by the lecturers were taken from an authentic speaking coursebook like "Speaking Extra," "Speaking Naturally," "Intermediate Communication Games," "Advanced Communication Games," and "Simple Speaking Activities." However, those books were considered less appropriate to implement for the students of generation $\mathrm{z}$ characteristics who are technology savvy. Therefore, the lecturers alternatively suggest a video of a native speaker speaking English as the students' speaking model by which they imitate the way of speaking. Moreover, the questionnaire yielded that the students preferred the use of audio-visual materials $(100 \%)$ for speaking classes other than text or course book with no speaking model. All of the students agreed (93\%) and strongly agreed (7\%) the need for a speaking model that encourages them to speak English like native-speaker.

The best way to advance the native speakers' exposure in speaking class is through watching native speakers' video talk. All the students are greatly supported (100\%) the use of technological materials such as YouTube videos in speaking classes. The majority of them believed that native speakers' videos are able promote their participation in speaking classes (96\%) and might affect their communication competence (78\%) especially to improve their pronunciation competence (57\%), vocabulary mastery (33\%), grammar advance (2\%), confidence $(2 \%)$, gesture $(2 \%)$, style $(2 \%)$, and accent $(2 \%)$. Both students $(93 \%)$ and lecturers $(100 \%)$ agreed upon the necessity for using native speakers' YouTube videos to improve students' speaking skill as well as most of the students believed that the videos could grant them lots of opportunities to be familiar with contextual concern in spoken English (96\%).

The results mentioned above of students' needs confirmed the urgency on audio-visual based material development to fulfill a primary instructional material for speaking courses. The audio-visual material supported by the students and lecturers is YouTube videos. Furthermore, the lecturers emphasize the need to find educational Youtube videos that are following the research by (Djahida (2017) that succeed in gaining the effectiveness of educational YouTube videos to enhance students' communicative competence, confidence, contextual language, and vocabulary enrichment. Also, another type of YouTube video like video-blog that can also be found on YouTube also one of the great sources in which native speakers are vlogging by talking about their activity in English directly in front of the camera.

All of the lecturers believed that videos taken from an authentic source produced by native speakers, like YouTube, would enhance students speaking competence especially and their listening comprehension to the authentic source, their pronunciation practice to be like a native speaker, and their communicative competence development generally. Moreover, they may also learn how native speakers' accents and dialects varied with each other by watching the video. The variety of topics used in selecting the video is also considered not to be bored for one type of video. The video can be directly spoken by the native speaker in front of the camera or can be in the form of a cut film scene or animated video. Those types of videos are best combined by in-class activities like retelling the video content, describing film scene, partner description, retelling an event watched in the video or cut film scene.

In line with the result of analysis of students' need, two instructional designs of speaking for beginner course were further accomplished based on the semester learning plan (SLP) and the lesson plan (RPP) that have been developed based on the three document of SLP developed by the lecturers of three universities and also referred to the need analysis results. SLP development was started by developing the learning outcomes of the course (Capaian Pembelajaran Mata Kuliah/ CPMK). Meanwhile, the content of SLP for the instructional material as the model consisted of six aspects. They are (1) week, (2) sublearning outcomes (expected), (3) indicators, (4) learning material, (5) methods, and assessment that is made up of four elements: (6) the type of assessment, (7) the criteria of assessment, (8) weight, and (9) the description of the assessment. Then, RPP was developed 
by completing the SLP with the description of learning experience based on four steps: introduction, main and closing, and follow up activity.

The learning outcomes of the course/ CPMK of the speaking for beginner course is that students are expected to be able to produce monologue and dialogue about various topics and demonstrate them based using precise English standards of pronunciation, fluency, and accuracy responsibly. Furthermore, the various topics mentioned on CPMK are mapped as the learning materials in SLP that were broken down into (a) introducing ourselves and others, (b) describing people, places, object, education and work, (c) talking about daily, weekend, experience, story and plan (d) asking with wh-words and general question, (e) moderating a panel discussion and (f) vlogging. The learning materials selected were brought about YouTube educational video adoption.

The expected final competencies of speaking for beginner courses are that students can demonstrate oral monologue and dialogue about the introduction, description, a panel discussion presentation, past narration, plan, questions with wh-words and general inquiry, and vlogging.

In the assessment, the types of speaking assessment made in the speaking for beginner course are oral assessment in the form of intensive, responsive, interactive, and extensive. Besides, the assessment criteria of speaking for beginner course is taken from (Brown,2001) the oral proficiency scoring categories that include pronunciation, fluency, and accuracy. Moreover, the speaking practice for speaking assessment planned to assign the course is a picture-cued task, oral-paraphrasing, retelling the speaker talk, role-play, doing a monologue, interviewing, telling story oral presentation, retelling story, and vlogs making. Finally, the learning method used in this course is blended learning where students can watch and learn the YouTube videos online and get the further learning experience about the video from the lecturer explanation in the speaking for the beginner classroom.

The draft of the model development was initiated by YouTube videos selection based on the learning material developed. Two kinds of the draft of the models were a coursebook with activities and assessment \& selected YouTube videos, including the links or URLs. Fourteen units of the coursebook entitled "speaking for the beginner: A way to speak like natives were designed based on the developed learning materials as written above. The title of each unit can be described as follow: 1) introduce yourself and others, 2) describe people's personality and appearance, 3) describe places and objects, 4) talk about education and work, 5) talk about daily and weekend routine, 6) moderating a panel discussion, 7) be a moderator in a panel discussion, 8) tell your experience, 9) tell your own story, 10) plan your future 11) ask with wh-words 12) ask general questions, 13) how to make a vlog, and 14) vlogging. Each unit includes a subs-unit introduction, warmer, activity 1: pronunciation guide and vocabulary building, activity 2: videos example, resource video, activity 3: speaking practice, and speaking tips. In each of the activities, the YouTube link in the form of Universal Resource Locator/ URL video can be accessed by the students by clicking the URL from the e-book, while the downloaded videos provided for the lecturer are on the CD. A video transcription attached below the URL to have students pay attention to the speakers' pronunciation, intonation and stress. The last part of the unit is speaking practice as an oral assessment described what students should perform at the end of the class. The Activities, along with the YouTube videos URL as well as assessments in the form of the assignment, are describing the picture-cued task, oral-paraphrasing, retelling the speaker talk, role-playing, doing a monologue, interviewing, telling a story, oral presentation, and vlogging.

The experts validated the draft of 'Speaking for Beginner: A way to speak like natives' are three lecturers of speaking course in the three universities. The aspects evaluated by the experts are content, instructional design, language, and presentation. Fifteen descriptions for 
the four aspects of the validation checklist were adapted from Beaudin (1996) and Balasubramanian, Shetty, \& Sathyanarayana (2018). The result of expert validation yielded that most of the descriptions in each aspect are generally suitable and acceptable enough $(78 \%)$. However, some revision had been further done by expert comments and suggestions.

The first revision made in the content aspect (79\%) was completed by adding the suggested assessment to the first topic to assign students a role as a moderator who introduces themselves and other speakers and the last topic to assign them a vlog making to include all the material given. The second revision in the instructional design aspect (78\%) where two of the video may not be easily integrated into the learning environment had been considered to replace it with another video based on the suggestion. In the language aspects (76\%), three revision with comprehensibility, grammatical accuracy, and intelligibility of the language used in some activities and assessments. The last revision was in terms of presentation aspects (78\%) by which a replacement of some video that was accordingly considered not to meet the simplicity and length principle.

When the revision from the expert had been completed, the results of revision were further presented to the designated expert to generate the accurateness of the revision. It yielded that the revision was well-made meaning that it was acceptable as instructional material for speaking for a beginner course. At that point, the model was ready for trial toward the real users for both students who attend speaking for the beginner course and the lecturers who are in charge of speaking for the beginner course.

After the revision was finished, the try-out of the model to the real classes was conducted to generate the model acceptability. A sum of fifty-nine students and three lecturers of speaking for a beginner course in four classes at the three universities participated in the try-out. Generally, the model was observed being well implemented by both lecturers and the students. Most of the videos and activities were easy to follow and understand. However, some of the videos with the British accent speaker mostly made the students confused due to lack of experience to listen to it. In this regard, the lecturers agreed to suggest adding related American video to make students able to distinguish them both. Another problem encountered by students was dictions in the assessment instruction that were difficult to understand and some created confusion among the students, like demonstrate, videotape, etc. The lecturer suggested replacing the word with the common and understandable for students in their first year in University.

The final model of 'Speaking for Beginner: A way to speak like native' was initially revised based on the suggestion from the lectures in the try-out stage and then evaluated by the students at the end of the try-out. Twenty-seven of them who were selected purposively were asked to evaluate the model based on the evaluation checklist to obtain their opinion on the 'Speaking for Beginner: A way to speak like natives'model acceptability in speaking classes.

The result of the students' evaluation showed good acceptability of the model. In general, all aspects are acceptable (85\%). The content aspect is accepted by $83 \%$. The percentage of each descriptor of the content aspect is as follows; the meaningfulness of the video content is $85 \%$, the understandability of the video content and written activity is $82 \%$, the understandability of the example is $84 \%$, and the appropriateness among the content of videos, activities, and assessments is $82 \%$. Therefore, all the descriptors' percentages are above $80 \%$ indicated that the content aspect of the model is suitable and applicable.

In the aspect of instructional design, the general percentage is $85 \%$, which is the highest percentage. The fulfillment of learning objective and students' needs got $86 \%$, while the material understanding from the video attained $83 \%$, and the video assistance of doing the assignment got $87 \%$. Above all the percentage generated that the instructional design aspect 
of the 'Speaking for Beginner: A way to speak like native' model was appropriate.

Furthermore, the language aspect attained a general percentage of $84 \%$. The descriptors' percentages can be described as the following. The appropriateness of the language used to the students' characteristics is $87 \%$, the understandability and comprehensibility among the language use of the videos, activities, and assessments is $84 \%$, the accurateness of grammatical in the language use of the activities and assessment is $84 \%$, and the clarity and intelligibility of the language use of the videos, activities, and assessments is $83 \%$. The overall percentage of the language aspect of the model also points to suitable and applicable.

In the last aspect, the presentation aspect also got the highest percentage at $85 \%$. The interesting way at the beginning of the video got $82 \%$, the simplicity of the procedure presented in the video is $84 \%$, the combination of the audio and video got $89 \%$, and the appropriateness of the length and pace of the video is $87 \%$. The high percentages of the presentation aspect descriptors brought about the applicability and the suitability of the presentation aspect. Above all, all the descriptors' percentage of the four aspects directed to the applicability and the suitability of the final model of 'Speaking for Beginner: A way to speak like a native.'

\section{CONCLUSION}

The current research and development were accomplished to fulfill the students of speaking for beginner needs on a primary instructional material for speaking for beginner courses by integrating it into audio-visual materials adopted from YouTube into the classroom. The idea of the development of educational YouTube videos-based instructional material of speaking for beginner courses is invented based on the result of need analysis and was appropriate to the characteristics of students of generation $\mathrm{z}$ who are technology savvy. The development was in the form of instructional material, semester learning plan (SLP) and lesson plan (RPP), as well as learning material along with YouTube videos adaptation. In addition to the development, the validation of the experts generally indicated good perceptions of the model with some revisions. The revised aspects are a few missing assessments in the content aspect, some inappropriate videos in the instructional design and the presentation aspects and some incomprehensible, unintelligible diction as well as inaccurate grammar in the language aspects. Another revision made is the attachment of American videos along with British videos for making a comparison of the accent and enrich student's understanding and competence on various English accents.

The final model of speaking for beginner instructional material development is so-titled 'Speaking for Beginner: A way to speak like natives' comprises of six learning materials; (a) introducing ourselves and others, (b) describing people, places, object, education and work, (c) talking about daily, weekend, experience, story and plan (d) asking with wh-words and general question, (e) moderating a panel discussion and (f) vlogging. The six learning materials are broken down into fourteen units, they are 1) introduce yourself and others, 2) describe people's personality and appearance, 3) describe places and objects, 4) talk about education and work, 5) talk about daily and weekend routine, 6) moderating a panel discussion, 7) be a moderator in a panel discussion, 8) tell your experience, 9) tell your own story, 10) plan your future 11) ask with wh-words 12) ask general questions, 13) how to make a vlog, and 14) vlogging. The Activities attached along with the YouTube videos as well as assessments suggested in speaking for beginner classrooms, are describing the picture-cued task, oral-paraphrasing, retelling the speaker talk, role-playing, doing a monologue, interviewing, telling a story, oral presentation, and vlogging.

The result of the acceptability of the model, which was evaluated by the students who 
attended speaking for a beginner course, has resulted in a high level of acceptability in $85 \%$ for all the components. Therefore, the conclusion drawn is that the developed instructional material 'Speaking for Beginner: A way to speak like natives' is suitable and applicable as a primary source supported the learning process in speaking for beginner course to create an updated learning experience by the course and students' needs as well as their characters so that the students can improve their speaking competence.

As a limitation of this study to further concern on the ensuing research is that the model is only suitable and applicable to the freshman of university students in their first-year study and limited to fulfill the students' of speaking for beginner classroom need in Lamongan region. Hence, it is suggested to employ need analysis in another region that may have different needs and characteristics and different level of speaking English. The use of educational Youtube videos as an audio-visual material in this research and development also restricted the study. Therefore, it is recommended to utilize another type of audio-visual material taken from another source.

\section{REFERENCES}

Balasubramanian, N., Shetty, A. P., \& Sathyanarayana Rao, T. (2018). Video Assisted Teaching Module (VATM): developed for primary caregivers on home care of schizophrenic patient. Nurse Care Open Access Journal, 5(6), 337-341. https://doi.org/10.15406/ncoaj.2018.05.00169

Beaudin, B. P. (1996). Instructional Video Evaluation Instrument. Journal of Extension, 34(3).

Brown H. Douglas, \& Heekyeong, L. (2015). Teaching by Principle: An Interactive Approach to Language Pedagogy. Teaching by Principles An Interactive Approach to Language Pedagogy (4th ed.). Pearson Higher Ed USA.

Cruse, E. (2018). Using Educational Video in the Classroom: Theory, Research and Practice. Library Video Company.

Depdiknas. (2000). Keputusan Menteri Pendidikan Nasional Republik Indonesia, Nomor 232 Tahun 2000 Tentang Pedoman Penyusunan Kurikulum Pendidikan Tinggi dan Penilaian Hasil Belajar Mahasiswa. Jakarta, Indonesia.

Djahida, L. (2017). The role of educational YouTube videos in improving EFL learners ' speaking skill: The case of second year LMD students of English at Biskra University. Biskra University. Retrieved from http://dspace.univbiskra.dz:8080/jspui/bitstream/123456789/10066/1/Labdi-Djahida2017pdf.pdf

Fauzan, U. (2014). Developing EFL Speaking Materials for the Second Semester Students of STAIN Samarinda. In English Language Curriculum Development: Implications for Innovations in Language Policy and Planning, Pedagogical Practices, and Teacher Professional Development. In Proceedings of The 61st TEFLIN (pp. 861-864). Solo: Sebelas Maret University.

Gall, M. D., Borg, W. R., \& Gall, J. P. (2007). Educational Research: An Introduction (8th ed.). Allyn \& Bacon.

Likert, R. (1932). A technique for the measurement of attitudes. Archives of Psychology, (140), 5-55.

Manurung, K. (2015). Improving the Speaking Skill Using Reading Contextual Internet-based Instructional Materials in an EFL Class in Indonesia. Procedia - Social and Behavioral Sciences, (176), 44-51. https://doi.org/10.1016/j.sbspro.2015.01.442

Santoso, D. (2014). Developing Speaking Materials for English Education Department Students Based On Accelerated Learning Approach. In ASAIHL Conference Nanyang Technological University Singapore (pp. 3-5).

Zahro, S. K. (2019). Native and Non-Native Listeners Perceptual Judgement of English 
Accentedness, Intelligibility, and Acceptability of Indonesian Speakers. Lingua Cultura, 13(1), 39-44. https://doi.org/10.21512/LC.V13I1.5362. 